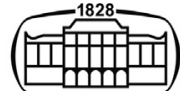

AKADÉMIAI KIADÓ

\section{Acta Veterinaria Hungarica}

DOI:

$10.1556 / 004.2020 .00042$ (c) 2020 Akadémiai Kiadó

\section{ORIGINAL ARTICLE}

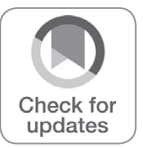

\title{
Retrograde flushing collection and freezing of dromedary camel epididymal spermatozoa with seminal plasma
}

DAVIDE MONACO $^{1 *}$ (D, MIGUEL BATISTA ${ }^{2}$, OLGA AMANN $^{3}$, BARBARA PADALINO ${ }^{4}$, WOUTER PIETERS ${ }^{3,5}$, MARIACRISTINA MORELLI ${ }^{1}$, GIANLUCA ACCOGLI ${ }^{6}$, SALVATORE DESANTIS $^{6}$ and GIOVANNI MICHELE LACALANDRA ${ }^{1}$

\footnotetext{
${ }^{1}$ Department of Veterinary Medicine, University of Bari Aldo Moro, Road to Casamassima km 3, 70010 Valenzano, BA, Italy

${ }^{2}$ Reproduction Clinic, Universitary Institute of Biomedical Research, University of Las Palmas Gran Canaria (ULPGC), Spain

${ }^{3}$ Museo del Campo Majorero, Oasis Park, Fuerteventura, Spain

${ }^{4}$ Department of Agricultural and Food Sciences, University of Bologna, Bologna, Italy

${ }^{5}$ Parc Animalier d'Auvergne, Ardes, France

${ }^{6}$ Department of Emergency and Transplantation of Organs (D.E.T.O.), University of Bari Aldo Moro, Italy
}

Received: February 7, $2020 \bullet$ Accepted: May 8, 2020

\begin{abstract}
The objectives of this study were to describe the parameters of dromedary camel epididymal spermatozoa collected by retrograde flushing (RF) technique and to evaluate the freezability of the collected sperm, diluted with and without the supplementation of seminal plasma (SP). Two experiments were conducted: in Experiment 1, ES were recovered within 6-8 h after castration; selected samples were diluted with a Tris-citrate egg-yolk glycerolated buffer and frozen. In Experiment 2, epididymides were stored for $24 \mathrm{~h}$ at $4{ }^{\circ} \mathrm{C}$ before $\mathrm{RF}$ and semen samples were frozen after dilution with a Tris-lactose eggyolk glycerolated extender with and without $15 \%$ SP. In Experiment 1, eight semen samples were obtained from ten epididymides with a mean of $500 \times 10^{6}$ total spermatozoa recovered, per flushed epididymis. Mean post-thaw motility and progressive motility were 75 and $17 \%$, respectively. In Experiment 2, 15 samples were collected, out of the 18 epididymides (mean number of collected spermatozoa: $700 \times 10^{6}$ ), and 13 of these samples were of excellent quality. Post-thaw parameters were not satisfactory but the supplementation of the freezing medium with 15\% SP improved the progressive motility and kinematic parameters of the spermatozoa.
\end{abstract}

\section{KEYWORDS}

dromedary camel, epididymides, seminal plasma, post-thaw, kinematic parameters

\section{INTRODUCTION}

The recovery of epididymal spermatozoa (ES) provides an alternative source of germoplasm for genetic conservation in case of events that preclude the reproductive life of males of high genetic value. Testes and epididymides could be stored at $4{ }^{\circ} \mathrm{C}$ for many hours, until it will be possible to collect and process the semen samples (Monteiro et al., 2011).

Given the peculiarities that limit the obtainment of suitable ejaculates from dromedary camel (DC) bulls (male aggressiveness, long mating time, failure of ejaculating with the 
artificial vagina, contamination of ejaculates), the collection of ES of adequate amount and good quality (i.e. from neutering or slaughterhouses material) could also help in the development of semen preservation and artificial insemination protocols (Monaco et al., 2016). Besides, ES could be used for overcoming the limitations imposed by the viscosity of the seminal plasma (SP) and as an experimental model for understanding the role of SP within semen cryopreservation protocols.

DC ES have been used for in vitro fertilisation and in vitro production of embryos and were obtained, in low number, through 'cutting' of the cauda epididymis (Khatir and Anouassi, 2006; Waheed et al., 2011). Despite the fact that ES have been collected with retrograde flushing (RF) in many animal species, in the DC this technique has been described only in two studies (Abdoon et al., 2013; Turri et al., 2013). However, other than sperm viability and total motility, the number of recovered sperm and other sperm parameters have not been described in detail. The objectives of this study were, therefore: (a) to describe the RF technique and the results of its application in the DC species; (b) to evaluate the freezability of collected ES and (c) to evaluate the effect of the addition of $15 \%$ SP to the freezing extender, on post-thaw semen parameters of the collected samples.

\section{MATERIALS AND METHODS}

Two separate experiments were performed in 2015-2016 and 2017-2019, respectively. The testicles used for the experiments were waste material resulting from ordinary castrations performed to prevent aggressive and restless behaviour of DC bulls assigned to tourism activities. In Experiment 1, RF was performed on 10 epididymides, within 6-8 h after neutering, whereas in Experiment 2, RF was performed on 18 epididymides, $24 \mathrm{~h}$ after neutering. Neutering was performed at Fuerteventura Oasispark; semen samples were collected and frozen at the University of Las Palmas Gran Canaria (Spain), whereas sperm kinematic parameters were evaluated at the University of Bari Aldo Moro (Italy).

\section{Experiment 1}

In this experiment, ten testes with annexed epididymides, obtained from five male camels (5 years of age), were transported at $4{ }^{\circ} \mathrm{C}$ and, $6-8 \mathrm{~h}$ after surgery, the epididymides with annexed deferent ducts were isolated. After the deferent duct was cannulated with a blunted needle (25 G; $5 \times 16 \mathrm{~mm}$ ), the epididymal tails were separated from the body, using a scalpel, proximally to the separation body/tail (considering the epididymis regions described by Fouchécourt et al. (2000) in stallions, the cut was made approximately in the region $\left.n^{\circ} 8\right)$.

RF was performed with a syringe filled with Tris-citrate buffer (Tris $247 \mathrm{mM}$; citric acid $87 \mathrm{mM}$; cephalexin $0.1 \%$ ) kept at room temperature (Bruemmer, 2006; Turri et al., 2013). Each sample collected from one epididymis was considered as an experimental unit. The obtained samples $(n=8)$ were evaluated for volume, sperm concentration, total and progressive motility, viability and morphology. The sperm concentration was assessed with a Neubauer haemocytometer, after diluting an aliquot of semen 1:100 with $0.5 \%$ formaldehyde solution. Total and progressive motility were assessed using a phase-contrast microscope, by two experienced operators: ten fields and a minimum of 400 spermatozoa were evaluated on sperm aliquots diluted to $15-30 \times 10^{6}$ spermatozoa $\times \mathrm{mL}^{-1}(\mathrm{spz} / \mathrm{mL})$ and kept at 37 ${ }^{\circ} \mathrm{C}$. The percentages of viable spermatozoa and morphological abnormalities (head, midpiece and tail) were evaluated on eosin/nigrosin $(\mathrm{E} / \mathrm{N})$ stained smears at $200 \times$ and $1,000 \times$ magnification, respectively, counting a minimum of 200 spermatozoa (Lorton, 2014).

\section{Sperm dilution and freezing}

Samples with a progressive motility $\geq 75 \%$ and a minimum concentration of $200 \times 10^{6} \mathrm{spz} / \mathrm{mL}(n=3$ samples $)$ were diluted to a final concentration of $100 \times 10^{6} \mathrm{spz} / \mathrm{mL}$ and a final composition of Tris $247 \mathrm{mM}$, citric acid $87 \mathrm{mM}$, glucose $66 \mathrm{mM}$, cephalexin $(0.1 \%)$ (modified from Batista et al., 2011), and clarified egg yolk $20 \%$. The clarified egg yolk was prepared according to Fernández-Santos et al. (2009). After $1.5 \mathrm{~h}$ of equilibration at $4{ }^{\circ} \mathrm{C}$, samples were further diluted to reach the final concentration of $4 \%$ glycerol and $50 \times 10^{6} \mathrm{spz} / \mathrm{mL}$. After an additional $1.5 \mathrm{~h}$ at $4{ }^{\circ} \mathrm{C}$, samples were loaded into pre-cooled $0.5-\mathrm{mL}$ straws, placed for $15 \mathrm{~min} 4 \mathrm{~cm}$ above liquid nitrogen (LN) level, and then plunged into LN.

\section{Thawing and post-thaw evaluation}

Thawing was performed at $46^{\circ} \mathrm{C}$ for $20 \mathrm{~s}$ (Crichton et al., 2015); for each sample, three straws were evaluated, after 10-min incubation at $37{ }^{\circ} \mathrm{C}$, for: viability, intact plasma membranes (IPMs), intact acrosomes (IAs), motility and progressive motility.

The sperm viability was evaluated on $\mathrm{E} / \mathrm{N}$ stained smears (Lorton, 2014). IPMs were evaluated through hypo-osmotic swelling test (HOS test) on a minimum of 200 spermatozoa (Skidmore et al., 2013). IAs were evaluated through a FITCH-PNA/DAPI fluorescence staining (Desantis et al., 2010; Rateb et al., 2019). Fluorescent images (jpg) were acquired at $20 \times$ magnification using a 488 -nm filter photomicroscope Eclipse Ni-U (Nikon, Japan) equipped with a digital camera (DS-U3, Nikon, Japan). Acrosomes with uniform green fluorescence were considered intact, whereas non-uniform/non-stained acrosomes were considered damaged and lost acrosomes, respectively (Fig. 1) (Morton et al., 2010).

Motility parameters were evaluated at $37^{\circ} \mathrm{C}$, through a Computer-Assisted Sperm Analyser (CASA) (Ivos12, Hamilton Thorne, USA). Since at the time of the experiment reference settings for DC sperm progressive motility were not available, the CASA system was set using the cut-off values reported in Table 1 (Experiment 1). Total and progressive motility, percentages of rapid, medium, slow and 


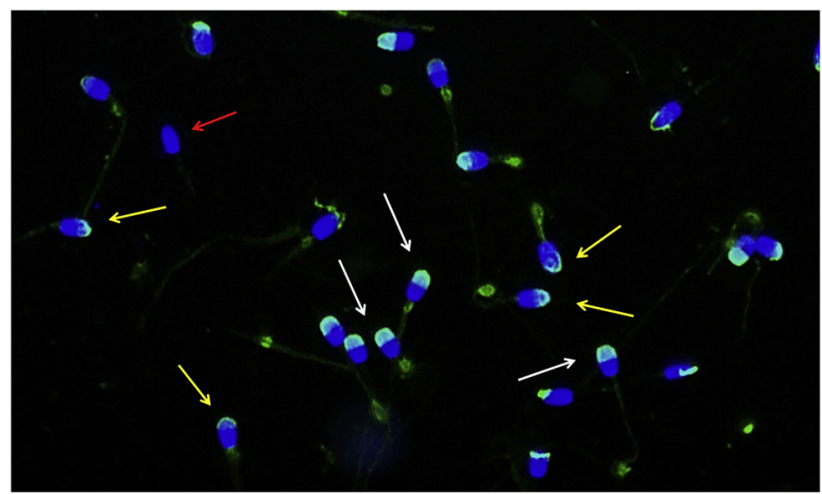

Fig. 1. Fluorescence staining (FITC-PNA/DAPI) of frozen-thawed epididymal spermatozoa.

* The red arrow indicates a lost acrosome, whereas yellow and white arrows indicate damaged and intact acrosomes, respectively

Table 1. Setting parameters for CASA evaluation of dromedary camel epididymal spermatozoa

\begin{tabular}{lcc}
\hline & Experiment 1 & Experiment $2^{\mathrm{a}}$ \\
\hline $\begin{array}{l}\text { Sample } \\
\text { acquisition rate }\end{array}$ & 60 images/s & 60 images $/ \mathrm{s}$ \\
Acquired fields & 7 & $7^{\mathrm{b}}$ \\
Motile sperms & $\mathrm{VAP}>20 \mu \mathrm{m} / \mathrm{s}$ & $\mathrm{VAP}>20 \mu \mathrm{m} / \mathrm{s}$ \\
Progressively & $\mathrm{VAP}>50 \mu \mathrm{m} / \mathrm{s}$ and & $\mathrm{VAP}>40 \mathrm{v} \mu \mathrm{m} / \mathrm{s}$ and \\
$\quad$ motile sperms & $\mathrm{STR}>75 \%$ & $\mathrm{STR}>70 \%$ \\
Slow spermatozoa & $20 \mu \mathrm{m} / \mathrm{s}<\mathrm{VAP}$ & $20 \mu \mathrm{m} / \mathrm{s}<\mathrm{VAP}$ \\
& $<30 \mu \mathrm{m} / \mathrm{s}$ & $<30 \mu \mathrm{m} / \mathrm{s}$ \\
\hline
\end{tabular}

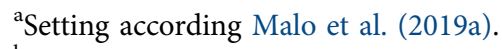

${ }^{\mathrm{b}}$ Modified from 5 to 7 fields.

static spermatozoa were evaluated in addition to average path velocity (VAP), straight line velocity (VSL), curvilinear velocity (VCL), amplitude of lateral head displacement $(\mathrm{ALH})$, beat cross frequency (BCF), straightness (STR), and linearity (LIN).

The above-mentioned semen parameters were evaluated again, after 3 -h incubation at $37{ }^{\circ} \mathrm{C}$ (Thermal Stress Test; ThS Test) (López-Urueña et al., 2015).

\section{Experiment 2}

The SP used in Experiment 2 was obtained through semen collections (with an artificial vagina) from two adult dromedary bulls of proven fertility. The selected ejaculates $(n=2)$ (non-contaminated, volume $\geq 4 \mathrm{~mL}$, sperm concentration $>100 \times 10^{6} \mathrm{spz} / \mathrm{mL}$ and total motility $\left.>80 \%\right)$ were allowed to spontaneously liquefy at $4{ }^{\circ} \mathrm{C}$, pipetted to reduce residual viscosity, and centrifuged twice at $1,000 \times g$ for 30 min. The two SP samples were checked for the absence of spermatozoa, then mixed with each other in equal volume and stored in aliquots at $-80{ }^{\circ} \mathrm{C}$ until use.

Testes and epididymides $(n=18)$ were collected following the castrations of 9 adult males (6-15 years of age), and kept at $4{ }^{\circ} \mathrm{C}$ for $24 \mathrm{~h}$, until RF.

\section{Experiment $2 \mathrm{~A}$}

The recovered ES samples (experimental units $n=15$ ) were evaluated for volume, concentration, and motility score (0-5; 0 : no motility; 1 : motility between 0 and 20\%, 2: motility between 20 and 40\%; 3: motility between 40 and 60\%; 4 : motility between 60 and $80 \%$; 5: motility between 80 and $100 \%$ ) (Monaco et al., 2015). Eosin/nigrosin stained smears were also prepared for the evaluation of sperm morphology to be carried out at a later time. Samples with a motility score $\geq 3$ $(n=13)$ were split into two portions (control and 15\% SP) and processed to reach the composition of Tris $268.28 \mathrm{mM} / \mathrm{L}$, citric acid $79.7 \mathrm{mM} / \mathrm{L}$, lactose $152.64 \mathrm{mM} / \mathrm{L}$, glucose 27.75 $\mathrm{mM} / \mathrm{L}, 20 \%$ clarified egg yolk, glycerol $4 \%$ (modified from ElBahrawy, 2017), and the final concentration of $50 \times 10^{6} \mathrm{spz} /$ $\mathrm{mL}$. Pre-freezing viability, total and progressive motility were evaluated by two operators, as described in Experiment 1, and samples showing pre-freezing progressive motility $\geq 40 \%$ ( $n=$ 13) were frozen with the same described technique.

Two straws for each sample and treatment were thawed, kept in Eppendorf tubes at $37^{\circ} \mathrm{C}$ for $10 \mathrm{~min}$, and then evaluated for viability $(\mathrm{E} / \mathrm{N})$ and total and progressive motility.

\section{Experiment 2B}

Twenty paired frozen samples were thawed, then evaluated for total and progressive motility, viability, and acrosome

Table 2. Experiment 1: Parameters of dromedary camel epididymal spermatozoa samples $(n=8)$ collected through retrograde flushing technique

\begin{tabular}{|c|c|c|c|c|c|c|}
\hline Parameter & Unit & Mean & St. Dev. & Median & Q1 & Q3 \\
\hline Volume & $\mathrm{mL}$ & 1.52 & 0.43 & 1.48 & 1.06 & 2.00 \\
\hline Sperm concentration & $\times 10^{6} \mathrm{spz} / \mathrm{mL}$ & 332.5 & 199.48 & 360 & 163 & 418 \\
\hline Total recovered sperms & $\times 10^{6} \mathrm{spz}$ & 508.13 & 319.14 & 540 & 163 & 830 \\
\hline Total motility & $\%$ & 74.63 & 10.54 & 76.00 & 62.50 & 85.00 \\
\hline Progressive motility & $\%$ & 65.63 & 15.22 & 70.00 & 50.00 & 78.75 \\
\hline Viable spermatozoa & $\%$ & 84.13 & 8.85 & 83.00 & 77.75 & 92.25 \\
\hline Abnormal sperm cells & $\%$ & 65.75 & 10.03 & 65.75 & 57.38 & 74.75 \\
\hline Abnormal tails $^{\mathrm{a}}$ & $\%$ & 63.12 & 10.43 & 60.75 & 50.63 & 67.75 \\
\hline Abnormal midpieces & $\%$ & 1.38 & 1.13 & 1.00 & 0.63 & 2.25 \\
\hline Abnormal heads & $\%$ & 1.25 & 1.07 & 1.00 & 0.25 & 2.25 \\
\hline
\end{tabular}

${ }^{\text {a }}$ Proximal and distal cytoplasmic droplets included. 
Table 3. Experiment 1: Pre-freezing parameters of dromedary camel epididymal spermatozoa semen samples $(n=3)$ diluted in a

Tris-citrate-glucose extender (20\% clarified egg yolk and $4 \%$ glycerol) and equilibrated for 3 hours at $4{ }^{\circ} \mathrm{C}$

\begin{tabular}{lcccccc}
\hline & & \multicolumn{5}{c}{ St. } \\
Parameter & Unit & Mean & Dev. & Median & Q1 & Q3 \\
\hline Viability & $\%$ & 95.2 & 3.68 & 96.5 & 91 & 98 \\
Motility & $\%$ & 85.7 & 4.01 & 86 & 81.5 & 89.5 \\
$\begin{array}{c}\text { Progressive } \\
\text { motility }\end{array}$ & $\%$ & 78.2 & 5.20 & 76.5 & 74 & 84 \\
$\begin{array}{c}\text { Intact plasma } \\
\text { membranes }\end{array}$ & $\%$ & 86.2 & 8.43 & 90 & 76.5 & 92 \\
\hline
\end{tabular}

integrity either after $10 \mathrm{~min}$ (T0) or after $60 \mathrm{~min}$ (T1) of incubation at $37{ }^{\circ} \mathrm{C}$. The same parameters were also evaluated through $\mathrm{E} / \mathrm{N}$ stained smears as well as by CASA, according to Malo et al. (2019a).

\section{Statistical analysis}

In Experiment 1, post-recovery, pre-freezing and post-thaw epididymal semen parameters were analysed through descriptive statistics; the results were expressed as mean, standard deviation, quartile 1 (Q1) and quartile 3 (Q3).

The parameters of ES samples collected in Experiment 2 were analysed through descriptive statistics. In Experiment $2 \mathrm{~A}$, pre-freezing and post-thaw semen parameters of control and treated (15\% SP) samples were analysed using the nonparametric Wilcoxon test. In Experiment 2B, post-thaw data recorded at $10 \mathrm{~min}(\mathrm{~T} 0)$ and $60 \mathrm{~min}(\mathrm{~T} 1)$ after thawing were tested for normality using the Anderson test. Since the distribution was non-normal, the data were log-transformed and then analysed using a 2-way ANOVA Generalized Linear Model procedure with treatments (Control and SP), time (T0 and T1) and their interaction as fix factors. Since the interaction was never significant, the original data (not normally distributed) were analysed using the U-Mann test to identify possible differences due to the treatment (Control and SP) and time (T0 and T1). The statistical significance was always set at $P<0.05$. All statistical analyses were performed using Genstat 19th edition.

\section{RESULTS}

\section{Experiment 1}

Table 2 summarises the semen parameters of the eight collected samples. A mean volume of $1.52 \mathrm{~mL}$ of spermbuffer solution with an average concentration of $332 \times 10^{6}$ $\mathrm{spz} / \mathrm{mL}$ was collected; the mean number of total recovered spermatozoa was $508 \pm 319 \times 10^{6}$. Within the eight samples, six showed total and progressive motility above 75 and $65 \%$, respectively. Descriptive statistics of pre-freezing and postthaw parameters of selected samples $(n=3)$ are reported in Tables 3 and 4, respectively.

\section{Experiment 2}

Descriptive parameters of the 15 samples collected in Experiment 2 are reported in Table 5. Overall, a mean volume of $1.57 \mathrm{~mL}$ of sperm-buffer solution with an average of $480.15 \times 10^{6} \mathrm{spz} / \mathrm{mL}$ was collected. The mean number of total recovered spermatozoa was $708 \pm 205 \times 10^{6}$. Eleven samples showed a motility score $\geq 4$ and, after equilibration, 13 samples were selected for freezing.

In experiment $2 \mathrm{~A}$, SP samples were not statistically different from control pre-freezing or post-thaw; a reduction of sperm viability was noticed after thawing but it was not

Table 4. Experiment 1: Post-thaw and post thermal stress test $\left(3 \mathrm{~h}\right.$ at $\left.37{ }^{\circ} \mathrm{C}\right)$ parameters of dromedary camel epididymal spermatozoa $(n=3)$ collected through retrograde flushing and frozen with a Tris-citrate-glucose extender ( $20 \%$ clarified egg yolk and $4 \%$ glycerol). Motility and kinematic parameters were evaluated through computer assisted sperm analyser

\begin{tabular}{|c|c|c|c|c|c|c|c|c|c|c|c|}
\hline \multirow[b]{2}{*}{ Parameter } & \multicolumn{6}{|c|}{ Post-thaw } & \multicolumn{5}{|c|}{ Post thermal stress (180 $\mathrm{min})$} \\
\hline & Unit & Mean & St. Dev. & Median & Q1 & Q3 & Mean & St. Dev. & Median & Q1 & Q3 \\
\hline Viability & $\%$ & 83.54 & 3.37 & 84.30 & 81.00 & 85.95 & 64.37 & 14.21 & 71.20 & 51.75 & 73.95 \\
\hline IPM & $\%$ & 69.38 & 9.56 & 68.10 & 61.50 & 77.05 & 56.06 & 7.69 & 55.25 & 51.33 & 62.40 \\
\hline Intact acrosome & $\%$ & 37.39 & 9.56 & 35.87 & 27.16 & 47.66 & 24.33 & 7.89 & 27.40 & 17.04 & 32.38 \\
\hline Motility & $\%$ & 75.33 & 3.91 & 77.00 & 71.50 & 78.50 & 41.33 & 18.03 & 39.00 & 26.00 & 57.50 \\
\hline Progressive motility & $\%$ & 17.22 & 4.89 & 16.00 & 13.50 & 20.50 & 6.89 & 4.54 & 6.00 & 3.50 & 10.00 \\
\hline Rapid & $\%$ & 60.22 & 6.26 & 61.00 & 55.00 & 65.00 & 28.44 & 17.29 & 29.00 & 12.00 & 41.50 \\
\hline Medium & $\%$ & 14.89 & 4.43 & 14.00 & 10.50 & 18.00 & 12.89 & 3.10 & 12.00 & 10.50 & 15.50 \\
\hline Slow & $\%$ & 5.56 & 2.46 & 5.00 & 3.50 & 7.00 & 3.00 & 1.00 & 3.00 & 2.00 & 3.50 \\
\hline VAP & $\mu \mathrm{m} / \mathrm{s}$ & 79.14 & 9.04 & 78.30 & 70.85 & 85.55 & 67.08 & 12.99 & 71.80 & 54.30 & 77.15 \\
\hline VSL & $\mu \mathrm{m} / \mathrm{s}$ & 45.42 & 7.60 & 43.20 & 40.15 & 49.25 & 36.78 & 7.82 & 39.40 & 28.30 & 42.95 \\
\hline VCL & $\mu \mathrm{m} / \mathrm{s}$ & 129.26 & 19.30 & 127.80 & 113.65 & 148.50 & 122.61 & 23.18 & 124.50 & 110.25 & 140.10 \\
\hline ALH & $\mu \mathrm{m} / \mathrm{s}$ & 4.64 & 0.53 & 4.60 & 4.20 & 5.10 & 4.86 & 0.95 & 5.20 & 4.35 & 5.55 \\
\hline BCF & $\mathrm{HZ}$ & 14.12 & 3.88 & 14.40 & 10.60 & 16.35 & 17.01 & 4.93 & 15.00 & 13.05 & 22.60 \\
\hline STR & $\%$ & 54.22 & 4.47 & 54.00 & 51.50 & 57.50 & 56.56 & 12.72 & 52.00 & 51.00 & 55.50 \\
\hline LIN & $\%$ & 35.89 & 5.33 & 36.00 & 31.50 & 40.50 & 30.56 & 3.81 & 32.00 & 27.00 & 33.00 \\
\hline
\end{tabular}

IPM: Intact plasma membranes; VAP: average path velocity; VSL: straight line velocity; VCL: curvilinear velocity; ALH: amplitude of lateral head displacement; BCF: beat cross frequency; STR: straightness; LIN: linearity. 
Table 5. Experiment 2: Sperm parameters of dromedary camel epididymal semen samples $(n=15)$ collected through retrograde flushing

\begin{tabular}{|c|c|c|c|c|c|c|}
\hline Parameter & Unit & Mean & St. Dev. & Median & Q1 & Q3 \\
\hline Volume & $\mathrm{mL}$ & 1.57 & 0.33 & 1.5 & 1.3 & 1.85 \\
\hline Sperm concentration & $\times 10^{6} \mathrm{spz} / \mathrm{mL}$ & 480.15 & 206.88 & 419 & 351.5 & 568 \\
\hline Total recovered sperms & $\times 10^{6} \mathrm{spz}$ & 708.57 & 205.18 & 668.8 & 605.95 & 840.75 \\
\hline Sperm motility $(0-5)$ & Score $(0-5)$ & 3.92 & 0.49 & 4 & 4 & 4 \\
\hline Abnormal sperm cells & $\%$ & 52.31 & 10.44 & 55 & 41.5 & 60.5 \\
\hline Abnormal tails ${ }^{\mathrm{a}}$ & $\%$ & 49.77 & 10.66 & 51 & 38 & 59 \\
\hline Abnormal midpieces & $\%$ & 2.54 & 1.85 & 3 & 0.5 & 4 \\
\hline Abnormal heads & $\%$ & 1.31 & 1.03 & 1 & 0.5 & 2 \\
\hline
\end{tabular}

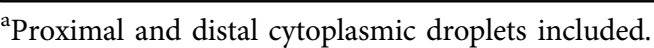

significantly different from control (Graphs 1 and 2). In experiment $2 \mathrm{~B}$, as expected, the incubation time had a significant negative effect on many semen parameters with reduction of values from T0 to T1 except for straightness $(P<0.01)$ : viability $(P<0.05)$, intact acrosome $(P<0.01)$, motility $(P<0.01)$, progressive motility $(P<0.01)$, rapid spz $(P<0.01)$, medium spz $(P<0.01)$, static spz $(P<0.01)$, VAP $(P<0.01)$ (Graphs 3-9). In contrast, the supplementation of $15 \%$ SP plasma to the freezing extender had a positive effect on progressive motility $(P<0.05)$ and sperm kinematic parameters: VAP $(P<0.05)$, VSL $(P<0.001)$, VCL $(P<$ $0.001)$, ALH $(P<0.05)$, STR $(P<0.05)$, LIN $(P<0.05)$ (Graphs 10-16).

\section{DISCUSSION}

In this paper the parameters of DC ES collected by the use of the RF technique are described in detail. The freezability of ES and the effect of SP supplementation on frozen-thawed semen parameters were also evaluated, for the first time. Eight out of ten (Experiment 1) and fifteen out of eighteen (Experiment 2) tails of epididymides were successfully flushed and 19 of the 23 obtained samples were considered to be of good/excellent quality (motility $>70 \%$ ). DC males reach puberty at the age of 3 years but the maximum
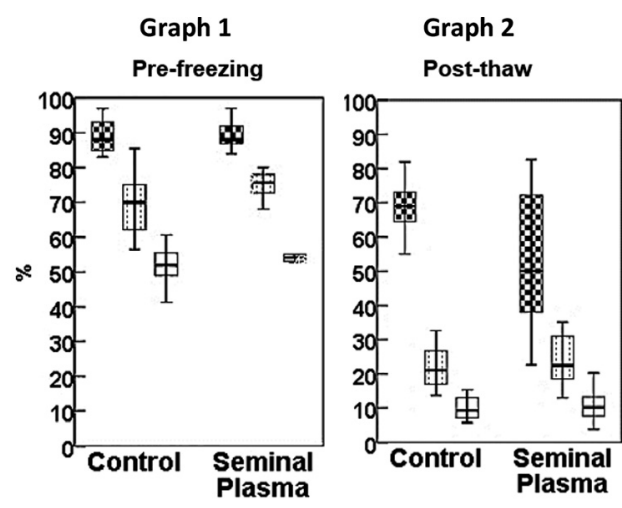

Graphs 1 and 2. Experiment 2A: Pre-freezing and post-thaw semen parameters of dromedary camel epididymal semen samples

$(n=13)$ diluted with a Tris-citrate-lactose extender $(20 \%$ clarified egg yolk and $4 \%$ glycerol) with and without the supplementation of $15 \%$ seminal plasma potential fertility is reached at the age of 7 years (El-Wishy, 1988). The higher amount of total spermatozoa collected in Experiment 2 (Tables 2 and 5) could be ascribed to the higher age of bulls in Experiment 2, but this hypothesis should be confirmed by further studies.

Waheed et al. (2011) obtained a mean total amount of $360 \times 10^{6} \mathrm{spz}$, with an average motility of $36 \%$, by mincing DC epididymal tails. Reference data about DC ES parameters are lacking in the literature; therefore, it is difficult to compare the results of the present study with those of other studies where ES were collected (Moawad et al., 2011; Wani and Hong, 2018).

Comparing RF with cutting, Turri et al. (2012) observed higher total motility and viability in bull epididymal sperm samples obtained through RF as compared to mincing. Santiago-Moreno et al. (2009) observed, in Capra pyrenaica, substantial benefits of the RF technique over cutting because of the larger number of recovered sperm cells and the reduced amount of post-thaw acrosome damage and morphological abnormalities. Hori et al. (2015) concluded that RF could be used as a standard technique in dogs and that cutting may be used when RF is unsuccessful. Evaluating the results of the present work, RF could be considered a satisfactory and easy-to-perform technique for recovering DC ES even though a true comparison should be made with the other techniques, for defining the gold standard procedure.

To the best of our knowledge, this is the first evaluation, by CASA, of the post-thaw motility and kinematic parameters of frozen-thawed DC ES samples. The post-thaw motility data observed in Experiment 1 (Table 4) are similar to those observed on frozen-thawed DC ejaculated spermatozoa, selected by single-layer centrifugation by Malo et al. (2019a), even though we used more restrictive parameters for the identification of progressively motile spermatozoa (Table 1).

In Experiment 2 semen samples showed acceptable prefreezing motility, albeit the post-thaw values were unsatisfactory (Graphs 4 and 11). The exact reason for these findings remain unknown but it could be hypothesised that the 24-h storage time of epididymides may have affected the freezability of sperm. Alternatively, the diluent used in Experiment 2 did not protect the ES efficiently from cryoinjury. Turri et al. (2014) observed that buck epididymis could be stored at $5{ }^{\circ} \mathrm{C}$ up to $48 \mathrm{~h}$ before the post-thaw effect 

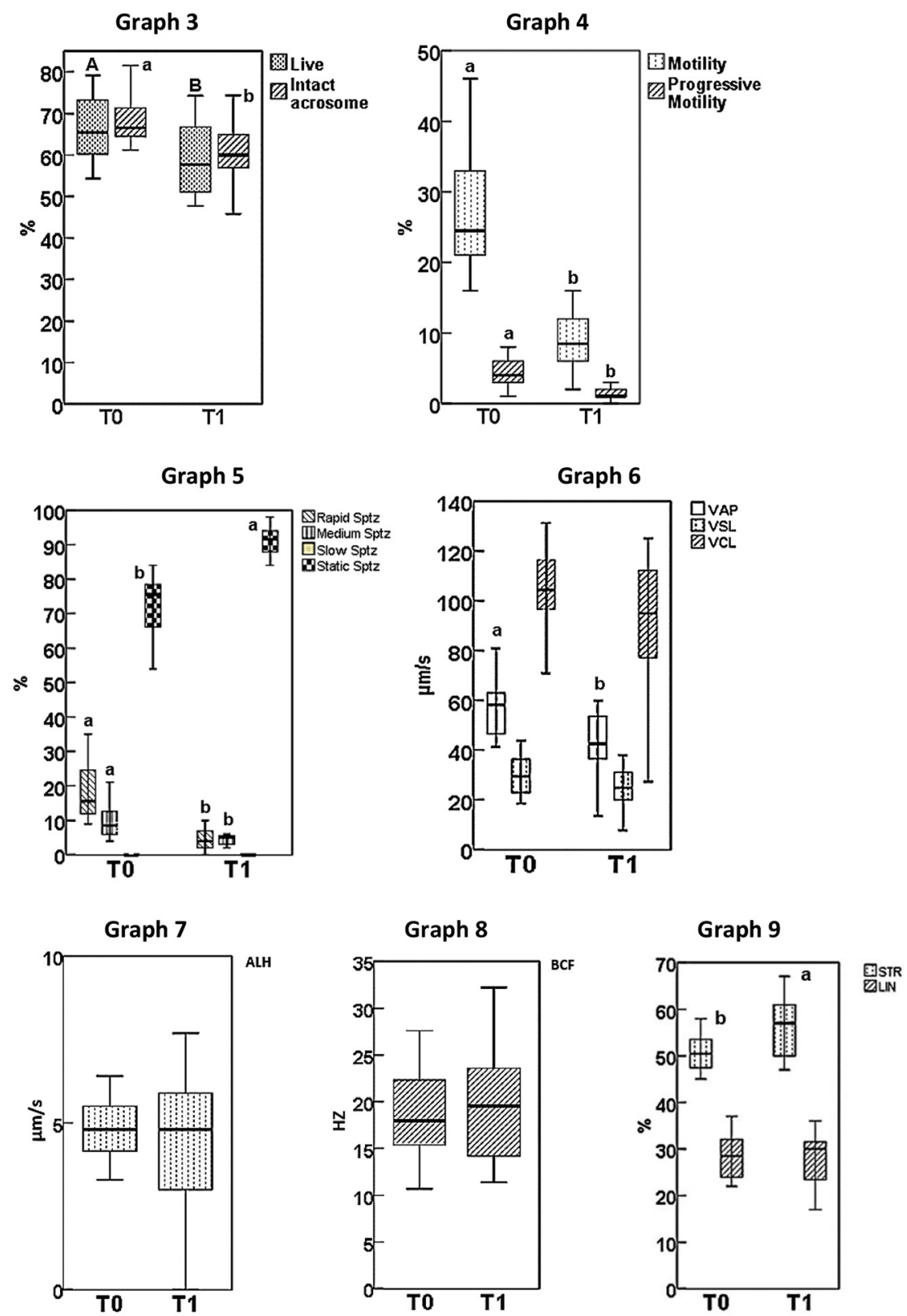

T0: 10 min at $37^{\circ} \mathrm{C}$ after thawing

T1: 60 minutes at $37^{\circ} \mathrm{C}$ after thawing

${ }_{A, B}$ For the same parameter, different letters indicate significant differences $(P<0.05)$.

${ }^{\mathrm{a}, \mathrm{b}}$ For the same parameter, different letters indicate significant differences $(P<0.01)$.

Graphs 3-9. Experiment 2B: Effect of time (T0, T1) on post-thaw semen and kinematic parameters of dromedary camel epididymal semen samples $(n=20)$ diluted with a Tris-citrate-lactose extender $(20 \%$ clarified egg yolk and $4 \%$ glycerol) extender. Motility and kinematic parameters were evaluated through computer assisted sperm analyser

of storage could manifest itself. Martins et al. (2009) found that post-thaw motility of bull spermatozoa was significantly reduced after a 72 -h storage time of epididymides as compared with 0,24 and $48 \mathrm{~h}$. In contrast, Monteiro et al. (2013) observed a significant decrease of post-thaw progressive motility in stallion spermatozoa collected from the epididymis after 12 -h storage at $5{ }^{\circ} \mathrm{C}$.

In previous studies, with subjective evaluation of ES postthaw motility, Abdoon et al. (2013) observed higher postthaw total motility $(47 \pm 5 \%)$ by using Ovixcell ${ }^{\circledR}$. By using
Shotor diluent, El-Badry et al. (2015) obtained total and progressive motility values of $47.4 \pm 1.3 \%$ and $32.8 \pm 1.3 \%$, respectively. More recently, post-thaw CASA evaluation of ejaculated spermatozoa revealed total and progressive motility values of $38.6 \pm 0.8 \%$ and $10 \pm 0.7 \%$ for spermatozoa diluted with Triladyl ${ }^{\circledR}$ (Swelum et al., 2019), and Malo et al. (2019b) observed total motility values ranging from $33 \%$ to $46 \%$ and progressive motility from 8 to $18.5 \%$ for spermatozoa frozen with Green Buffer ${ }^{\circledR}$. In the light of the above-mentioned studies and according to the present 
Graph 10
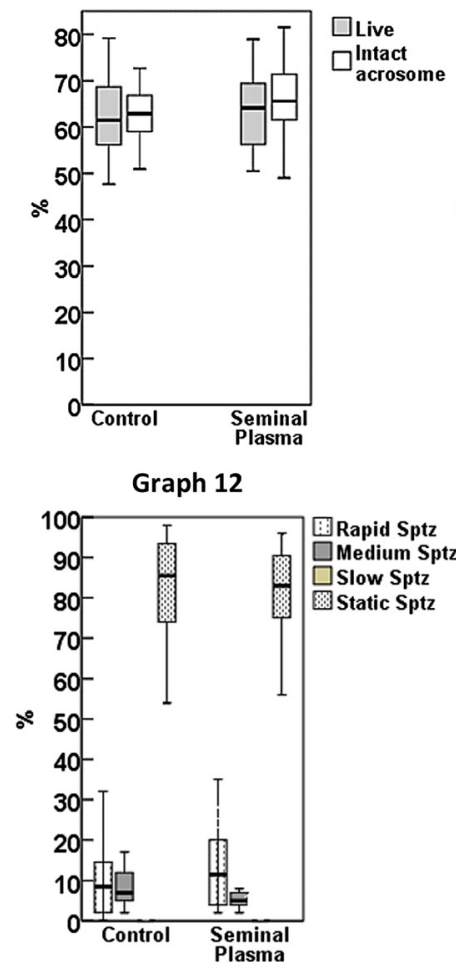

Graph 11

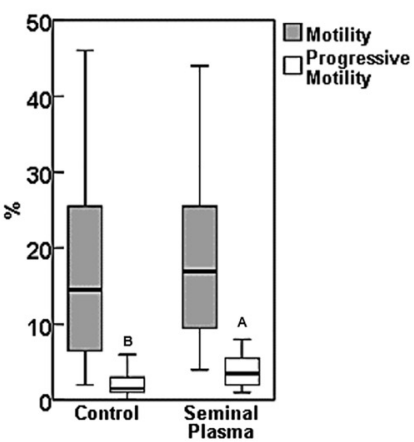

Graph 13

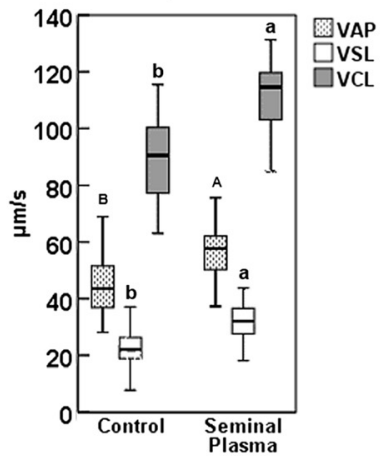

Graph 14

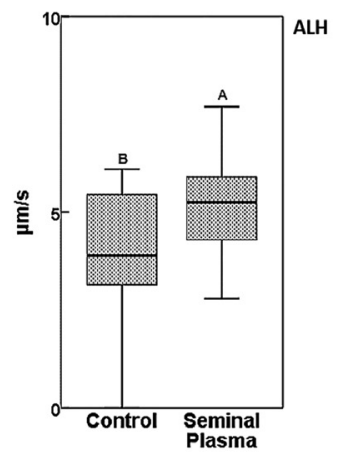

Graph 15

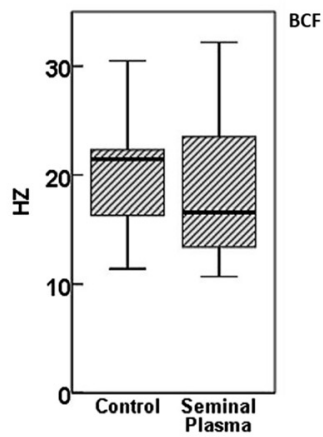

Graph 16

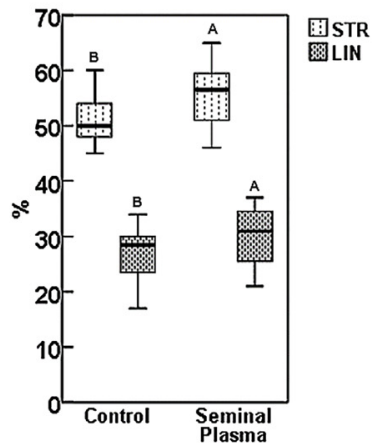

${ }^{A, B}$ For the same parameter, different letters indicate significant differences $(P<0.05)$

a,b For the same parameter, different letters indicate significant differences $(P<0.001)$.

Graphs 10-16. Experiment 2B. Post-thaw semen and kinematic parameters of dromedary camel epididymal semen samples $(n=20)$ diluted with a Tris-citrate-lactose extender (20\% clarified egg yolk and $4 \%$ glycerol) with and without $15 \%$ seminal plasma

results, the effects of the epididymal storage time and of the freezing diluents on post-thaw ES motility parameters require further investigations.

This is the first study that evaluated the effect of SP supplementation on the post-thaw parameters of DC ES. The 15\% SP supplementation was chosen considering the work of Kershaw-Young and Maxwell (2011) who found that 10 and $25 \%$ SP had a protective effect on alpaca ES maintained at $37{ }^{\circ} \mathrm{C}$ for $3 \mathrm{~h}$, as compared with control $(0 \%$ SP), 50 and $100 \%$ SP dilution. Contrary to expectations (reduced sperm motility due to a residual micro-viscosity was also hypothesised as a side effect), the CASA analysis revealed that SP had a significant effect on some sperm kinematic parameters (Graphs 10-16). Fumuso et al. (2018) observed that llama ES incubated at $37^{\circ} \mathrm{C}$ for $3 \mathrm{~h}$ had higher progressive motility when 10 or $50 \%$ SP was added as compared to $100 \%$ SP supplementation. In the same species, Fumuso et al. (2019) observed that the pre-freezing supplementation of $10 \%$ SP leads to higher than $50 \%$ post-thaw motility (subjective evaluation). However, significant differences were not detected in either experiment comparing 10 and 50\% SP supplementation with control samples.

In stallion semen preservation protocols, addition of 5$20 \%$ SP is recommended since beneficial effects on sperm motion characteristics for up to $96 \mathrm{~h}$ of storage have been observed (Neuhauser et al., 2015). Subjective motility 
evaluations showed that the pre-freezing exposure of stallion ES to SP could improve the pre-freezing but not the postthaw motility values (Tiplady et al., 2002). It has also been observed that the kinematic parameters of stallion sperm are positively influenced by the post-thaw supplementation of SP and that the sperm kinematic values improve until the limit of $50 \%$ SP is added to the extender (Neuhauser et al., 2015, 2018). According to the present results, it seems that there is a positive effect of SP on post-thaw motility of DC ES as observed also in the equine species.

In conclusion, RF is a valuable procedure for the collection of DC ES and the obtained samples could be used for evaluating the DC semen processing procedure. The supplementation of $15 \%$ SP seems to have beneficial effects on post-thaw motility and sperm kinematic parameters of DC ES.

\section{ACKNOWLEDGEMENTS}

This study is dedicated to the memory of Prof. Carlos Gutiérrez Cabrera (ULPGC), expert in ruminant and camelid medicine who tragically died on 8 March 2019. With friendly and gentle manners, and always with a smile, Carlos provided technical and moral support and delighted everyone with his positive attitude during all phases of this work. We miss you a lot Carlos, Rest in Peace.

The authors wish to express their gratitude to the direction and staff of the Oasis Park Fuerteventura for their contribution to the development of the study.

\section{REFERENCES}

Abdoon, A. S., Kandil, O. M., Pizzi, F., Turri, F., Atrash, A. and Sabra, H. A. (2013): Effect of semen extender on cryopreservation and fertilization rates of dromedary camel epididymal spermatozoa. In: Seri, H. I., Eisa, M. O. and Mokhtar, R. (eds) Proceedings of the International Scientific Conference of Camel Research and Production (ISCCRP), 17-18 April 2013, Khartoum, Sudan. pp. 75-82.

Batista, M., Niño, T., Santana, M., Alamo, D., Castro, N., Reyes, R., González, .F, Cabrera, F. and Gracia, A. (2011): Influence of the preservation temperature $\left(37,20,4,-196{ }^{\circ} \mathrm{C}\right)$ and the mixing of semen over sperm quality of Majorera bucks. Reprod. Domest. Anim. 46, 281-288.

Bruemmer, J. E. (2006): Collection and freezing of epididymal stallion sperm. Vet. Clin. Equine 22, 677-682.

Crichton, E. G., Pukazhenthi, B. S., Billah, M. and Skidmore, J. A. (2015): Cholesterol addition aids the cryopreservation of dromedary camel (Camelus dromedarius) spermatozoa. Theriogenology 83, 168-174.

Desantis, S., Ventriglia, G., Zizza, S., Nicassio, M., Valentini, L., Di Summa, A. and Lacalandra, G. M. (2010): Lectin-binding sites on ejaculated stallion sperm during breeding and non-breeding periods. Theriogenology 73, 1146-1153.
El-Badry, D. A., Scholkamy, T. H., Anwer, A. M. and Mahmoud, K. G. M. (2015): Assessment of freezability and functional integrity of dromedary camel spermatozoa harvested from caput, corpus and cauda epididymides. Alex. J. Vet. Sci. 44, 147-158.

El-Bahrawy, K. A. (2017): The influence of caffeine supplementation and concerted utilization of enzymatic and mechanical semen liquefaction on freezability of dromedary camel spermatozoa. Int. J. Vet. Sci. Med. 5, 121-127.

El-Wishy, A. B. (1988): Reproduction in the male dromedary camel (Camelus dromedarius): a review. Anim. Reprod. Sci. 17, 217241.

Fernández-Santos, M. R., Martínez-Pastor, F., Matias, D., Domínguez-Rebolledo, A. E., Esteso, M. C., Montoro, V. and Garde, J. J. (2009): Effects of long-term chilled storage of red deer epididymides on DNA integrity and motility of thawed spermatozoa. Anim. Reprod. Sci. 111, 93-104.

Fouchécourt, S., Métayer, S., Locatelli, A., Dacheux, F. and Dacheux, J-L. (2000): Stallion epididymal fluid proteome: qualitative and quantitative characterization; secretion and dynamic changes of major proteins. Biol. Reprod. 62, 17901803.

Fumuso, F. G., Giuliano, S. M., Chaves, M. G., Neild, D. M., Miragaya, M. H. and Carretero, M. I. (2019): Evaluation of the cryoprotective effect of seminal plasma on llama (Lama glama) spermatozoa. Andrologia 51, art. no. e13270.

Fumuso, F. G., Giuliano, S. M., Chaves, M. G., Neild, D. M., Miragaya, M. H., Gambarotta, M. C. and Carretero, M. I. (2018): Seminal plasma affects the survival rate and motility pattern of raw llama spermatozoa. Anim. Reprod. Sci. 192, 99106.

Hori, T., Atago, T., Kobayashi, M. and Kawakami, E. (2015): Influence of different methods of collection from the canine epididymides on post-thaw caudal epididymal sperm quality. J. Vet. Med. Sci. 77, 625-630.

Kershaw-Young, C. M. and Maxwell, W. M. C. (2011): The effect of seminal plasma on alpaca sperm function. Theriogenology 76, 1197-1206.

Khatir, H. and Anouassi, A. (2006): The first dromedary (Camelus dromedarius) offspring obtained from in vitro matured, in vitro fertilized and in vitro cultured abattoir-derived oocytes. Theriogenology 65, 1727-1736.

López-Urueña, E., Alvarez, M., Gomes-Alves, S., Anel-López, L., Martínez-Rodríguez, C., Manrique, P., Borragan, S., Anel, L. and de Paz, P. (2015): Optimization of conditions for long-term prefreezing storage of brown bear sperm before cryopreservation. Theriogenology 84, 1161-1171.

Lorton S. P. (2014): Evaluation of semen in the andrology laboratory. In: Chenoweth, P. J. and Lorton, P. (eds) Animal Andrology Theories and Applications, $\mathrm{CAB}$ International, Wallingford, UK. pp. 100-143.

Malo, C., Elwing, B., Soederstroem, L., Lundeheim, N., Morrell, J. M. and Skidmore, J. A. (2019a): Effect of different freezing rates and thawing temperatures on cryosurvival of dromedary camel spermatozoa. Theriogenology 125, 43-48.

Malo, C., Grundin, J., Morrell, J. M. and Skidmore, J. A. (2019b): Individual male dependent improvement in post-thaw dromedary camel sperm quality after addition of catalase. Anim. 
Reprod. Sci. https://doi.org/10.1016/j.anireprosci.2019.106168. Epub 2019 August 20.

Martins, C. F., Driessen, K., Costa, P. M., Carvalho-Neto, J. O., de Sousa, R. V., Rumpf, R. and Dode, M. N. (2009): Recovery, cryopreservation and fertilization potential of bovine spermatozoa obtained from epididymides stored at $5{ }^{\circ} \mathrm{C}$ by different periods of time. Anim. Reprod. Sci. 116, 50-57.

Moawad, A. R., Darwish, G. M., Badr, M. R. and El-Wishy, A. B. (2011): In vitro fertilization of dromedary camel (Camelus dromedarius) oocytes with epididymal spermatozoa. Reprod. Fertil. Dev. 24, 192-193.

Monaco, D., Fatnassi, M., Padalino, B., Aubé, L., Khorchani, T., Hammadi, M. and Lacalandra, G. M. (2015): Effects of a GnRH administration on testosterone profile, libido and semen parameters of dromedary camel bulls. Res. Vet. Sci. 102, 212-216.

Monaco, D., Fatnassi, M., Padalino, B., Hammadi, M., Khorchani, T. and Lacalandra, G. M. (2016): Effect of $\alpha$-amylase, papain, and Spermfluid ${ }^{\circledR}$ treatments on viscosity and semen parameters of dromedary camel ejaculates. Res. Vet. Sci. 105, 5-9.

Monteiro, G. A., Guasti, P. N., Rocha, A. S., Martin, I., SanclerSilva, Y. F. R., Dell'Aqua, C. P. F., Dell'Aqua, J. A. and Papa, F. O. (2013): Effect of storage time and temperature of equine epididymis on the viability, motion parameters, and freezability of epididymal sperm. J. Equine Vet. Sci. 33, 169-173.

Monteiro, G. A., Papa, F. O., Zahn, F. S., Dell' Aqua, J. A., Melo, C. M., Maziero, R. R. D., Avanzi, B. R., Alvarenga, M. A. and Guasti, P. N. (2011). Cryopreservation and fertility of ejaculated and epididymal stallion sperm. Anim. Reprod. Sci. 127, 197-201.

Morton, K. M., Evans, G. and Maxwell, W. M. C. (2010): Effect of glycerol concentration, Equex $\mathrm{STM}^{\circledR}$ supplementation and liquid storage prior to freezing on the motility and acrosome integrity of frozen-thawed epididymal alpaca (Vicugna pacos) sperm. Theriogenology 74, 311-316.

Neuhauser, S., Dörfel, S. and Handler, J. (2015): Dose-dependent effects of homologous seminal plasma on motility and kinematic characteristics of post-thaw stallion epididymal spermatozoa. Andrology 3, 536-543.

Neuhauser, S., Gösele, P. and Handler, J. (2018): Combined singlestraw packaging of cryopreserved stallion epididymal sperm and separated homologous seminal plasma. J. Equine Vet. Sci. 71, 57-63.

Rateb, S. A., Monaco, D., El-Bahrawy, K. A., Khalifa, M. A., Abd ElHamid, I. S, Kamel, A. M., Accogli, G., Lacalandra, G. M. and
Desantis, S. (2019): Ramifications of protease-based liquefaction of camel semen on physical, kinematic and surface glyco-pattern of cryopreserved spermatozoa. Anim. Reprod. Sci. 208, 106-121.

Santiago-Moreno, J., Astorga, R. J., Luque, I., Coloma, M. A., Toledano-Díaz, A., Pulido-Pastor, A., Gómez-Guillamon, F., Salas-Vega, R. and López-Sebastián, A. (2009): Influence of recovery method and microbial contamination on the response to freezing-thawing in ibex (Capra pyrenaica) epididymal spermatozoa. Cryobiology 59, 357-362.

Skidmore, J. A., Morton, K. M. and Billah, M. (2013): Artificial insemination in dromedary camels. Anim. Reprod. Sci. 136, 178-186.

Swelum, A. A. A., Saadeldin, I. M., Ba-Awadh, H., Al-Mutary, M. G., Moumen, A. F., Alowaimer, A. N. and Abdalla, H. (2019): Efficiency of commercial egg yolk-free and egg yolk-supplemented Tris-based extenders for dromedary camel semen cryopreservation. Animals 9, 1-15.

Tiplady, C. A., Morris, L. H.-A. and Allen, W. R. (2002): Stallion epididymal spermatozoa: Pre-freeze and post-thaw motility and viability after three treatments. Theriogenology $\mathbf{5 8}$, 225-228.

Turri, F., Kandil, O. M., Abdoon, A. S., Sabra, H., El Atrash, A. and Pizzi, F. (2013). In: Conservation of Camel Genetic Resources: Epididymal Sperm Recovery. Proc. School of Oriental and African Studies (SOAS) III Camel Conference, 29-30 April 2013, London. https://www.soas.ac.uk/camelconference2013/.

Turri, F., Madeddu, M., Gliozzi, T. M., Gandini, G. and Pizzi, F. (2012): Influence of recovery methods and extenders on bull epididymal spermatozoa quality. Reprod. Domest. Anim. 47, 712-717.

Turri, F., Madeddu, M., Gliozzi, T. M., Gandini, G. and Pizzi, F. (2014): Effect of testicles post mortem storage on goat frozenthawed epididymal sperm quality as a tool to improve genebanking in local breeds. Animal 8, 440-447.

Waheed, M. M., Al-Eknah, M. M. and El-Bahr, S. M. (2011): Some biochemical characteristics and preservation of epididymal camel spermatozoa (Camelus dromedarius). Theriogenology 76, $1126-1133$

Wani, N. A. and Hong, S. (2018): Intracytoplasmic sperm injection (ICSI) of in vitro matured oocytes with stored epididymal spermatozoa in camel (Camelus dromedarius): Effect of exogenous activation on in vitro embryo development. Theriogenology 113, 44-49. 